\title{
DIGITALCOMMONS
}

@WAYNESTATE —

Wayne State University

Administrative and Organizational Studies

College of Education

1-1-2005

\section{Does Media Affect Learning: Where Are We Now?}

Nancy B. Hastings

Wayne State University

Monica W. Tracey

Wayne State University, Monicatracey@wayne.edu

\section{Recommended Citation}

Hastings, N. B., \& Tracey, M. W. (2005). Does media affect learning: where are we now?. TechTrends, 49(2), 28-30.

Available at: http://digitalcommons.wayne.edu/coe_aos/15

This Article is brought to you for free and open access by the College of Education at DigitalCommons@WayneState. It has been accepted for inclusion in Administrative and Organizational Studies by an authorized administrator of DigitalCommons@WayneState. 
Instructional Media 1

Running Head: INSTRUCTIONAL MEDIA

Does media affect learning: Where are we now?

Nancy B. Hastings

Wayne State University

Monica W. Tracey

Oakland University 
Instructional Media 2

\begin{abstract}
It is time to extinguish the argument as to whether or not the media of 1983 could, should or would affect learning outcomes. The technological advances that have occurred in the 20 years since Clark sparked the debate and Kozma fanned the flames have made the question irrelevant. High-speed, portable, reasonably priced computers, the Internet, and the World Wide Web have changed the face of how, when, and where learning occurs. The media of 2004 does affect learning. The question is no longer if; the question is how.
\end{abstract}


In 1983, Clark declared that instructional methods determine how effective a piece of instruction is and that media's only influence is on cost and distribution. His argument (Clark, 1983) was "media are mere vehicles that deliver instruction but do not influence student achievement any more than the truck that delivers our groceries causes changes in our nutrition" (p. 445). In 1991 and again in 1994 Kozma challenged Clark's position, contending that the unique attributes of certain media can affect both learning and motivation. His argument (Kozma, 1994) was "if there is no relationship between media and learning it may be because we have not yet made one" (p. 7). Thus began the great media effects debate.

Whether or not the media of 1983 could, would or should affect learning has never been resolved, and likely never will be. Nor does it matter. Media capabilities have changed dramatically since 1983 . And yet the debate has remained frozen in time, still focusing on Clark's delivery truck metaphor and Kozma's unique attributes position. To be relevant, we must thaw out the debate, bringing it forward to the year 2004. In doing so, the question is reframed and our positions reevaluated. If we were to discuss these issues today, in 2004, what resolution would we come to? Would the arguments be the same as they were 10 or 20 years ago? Or do the changes in modern technologies allow scholars to come to a consensus, providing closure at long last to the great media effects debate?

The technological advances of the past 20 years have added substance to Kozma's position, providing an ever-increasing array of attributes, which would be costly if not impossible to replicate in the traditional classroom. These same advances have 
simultaneously transformed Clark's delivery truck into a supersonic jet, affecting learning by getting instruction to its destination faster, fresher, and less expensively than was conceivable in 1983. We believe that in discussing the roles media plays in learning in the year 2004, the focus of the conversation should not be if, but how media affects learning.

\section{Computers and Learning}

Most instructional media, such as print and video, have the same attributes and are compatible with the same instructional methods and strategies today as they were in 1983. Focusing on that which remains unchanged will do nothing to stamp out the debate. We must instead turn our attention to 2004 and the one medium whose attributes have changed dramatically since 1983; the computer.

In 1983 computers could only communicate with each other if they were physically connected to the same mainframe or server (Willis, Johnson \& Dixon, 1983). They were not portable or easily programmable. The Internet and the World Wide Web were unheard of. Software to support virtual classrooms, online synchronous communication, and just in time learning did not exist. In 2004, any computer user with Internet access has free or relatively inexpensive access to search engines, public databases and both public and private educational materials. The computers of 2004 provide strong support for Kozma's $(1991,1994)$ unique attributes argument while simultaneously refuting Clark's $(1983,1994)$ position that media is interchangeable.

Clark: Media or Method

Clark never suggested that media selection is irrelevant, or that it be made with no regard to the methods, learners or instructional design. His position has always been that 
any given method can be developed for delivery by more than one medium and be equally effective at facilitating learning, therefore the designer is tasked with choosing the best way to "package essential instructional methods based on available resources and the cost-effectiveness qualities of media attributes for specific learners and learning goals" (p. 23). In 1983, and even 1994, Clark's argument was valid. In 2004, it is valid for many, but not all, instructional method and delivery medium pairings. We assert that today, computers have unique, non-replicable, capabilities and therefore can support instructional methods that other media cannot.

\section{Kozma: Unique Attributes}

Kozma's (1991) argument has been that "the capabilities (attributes) of a particular medium, in conjunction with methods that take advantage of these capabilities, interact with and influence the ways learners represent and process information and may result in more or different learning when one medium is compared to another for certain learners and tasks" (p. 179). He does not contend that media alone can influence learning, rather that media's ability to influence learning is dependent upon the instructional methods employed by the design and how those methods exploit the capabilities or attributes of the medium.

How valid this argument was in 1983 is irrelevant. What is relevant is whether or not any of the media available in 2004 have unique, non-replicable capabilities that, when properly exploited by the instructional design, can affect learning. The unique capabilities of the computer, in conjunction with the Internet and the World Wide Web, provide unquestionable support for Kozma's argument. Only computers can provide access to databases night or day, thousands of miles away. Only computers can foster the 
development of virtual classrooms. Only computers can provide interactive, anytime, anywhere, learner controlled training.

\section{Discussion}

What we have presented above are our views. We believe the technological advances that have occurred in the past 21 years must be considered in any further discussion of media affects. We believe modern technology has turned the delivery truck into a supersonic jet. We believe that the attributes of modern media, specifically computers, the Internet and the World Wide Web, are not replaceable and that they do affect learning. Support for these opinions must come from empirical research, which ironically has been the major stumbling block in resolving the original debate.

Kozma, in developing and defending his position, cited multiple media comparison studies that indicated that the use of computers increased motivation, increasing the amount of time the learner was willing to spend interacting with the content (Kozma, 1991, 1994). His position, supported by Keller's ARCS model and Carroll's Model of School Learning, is that increased motivation and time on task increase learning outcomes (Carroll, 1963; Keller, 1987).

Clark questioned the validity of this research. His argument was that media comparison studies failed to hold all other variables constant, and therefore did not provide viable proof that the media was responsible for any noted affects on learning. Clark's position was that changes in learning outcomes were tied to variations in methods and strategies employed in the experimental treatments, not the media and that unless all variables could be controlled, media comparison studies should be abandoned (Clark, 1983, 1994). 
Clark's point is valid. Media comparison studies will never succeed in resolving the media effects debate.

\section{Conclusion}

A careful review of the arguments and counter arguments presented by Clark $(1983 ; 1994)$ and Kozma $(1991 ; 1994)$, responses published in the past 20 years (Jonassen, Campbell \& Davidson, 1994; Morrison, 1994; Reiser, 1994; Shrock, 1994) and existing instructional design literature (Morrison, Ross \& Kemp, 2001; Reiser \& Dick, 1996; Smith \& Ragan, 1999) indicates there is, and always has been, significantly more agreement on this subject than the debate would indicate.

Clark never said that a textbook could deliver an instructional method requiring the use of a 3-dimensional graphic representation as effectively as a computer, nor did Kozma maintain that the computer was the only medium with the capabilities to do so.

Both acknowledged that the two instructional components - the instructional methods and the delivery medium - must be aligned to facilitate learning.

The debate is and always has been about the ability of more than one medium to support a selected instructional method, whether or not any given medium has capabilities that cannot be replicated by another medium, and the validity of the research.

We believe that today, in 2004:

- Computers are capable of supporting instructional methods that other media are not

- Computers, by means of their unique capabilities, affect learning

- Computers are often the use of the most cost-effective, efficient delivery method for any given unit of instruction 
- Acknowledge the limitations of media comparison studies

- Acknowledge the need to align the message, the medium and the learning task

- Agree that some media are interchangeable

- Support the use of the most cost-effective, efficient delivery method for any given unit of instruction

We believe that after 21 years it is time to reframe the original debate to ask not if, but how media affects learning. We agree that media comparison studies are inherently flawed and support the argument that we must identify research designs that will provide answers to this question in significantly less time. 


\section{References}

Carroll, J.B. (1963). A model of school learning. Teachers College Record, 64, 723-733.

Clark, R. (1983). Reconsidering research on learning from media. Review of Educational Research, 53(4), 445-449.

Clark, R. (1994). Media will never influence learning. Educational Technology, Research and Development, 42(2), 21-29.

Heinich, R., Molenda, M. \& Russell, J. (1982). Instructional media and the new technologies of instruction. New York: John Wiley \& Sons.

Jonassen, D.H., Campbell, J.P., Davidson, M.E. (1994). Learning with media: restructuring the debate. Educational Technology, Research and Development, $42(2), 31-39$.

Keller, J.M. (1987). The systematic process of motivational design. Performance and Instruction, 26(10), 1-8.

Kozma, R. (1991). Learning with media. Review of Educational Research, 61(2), 179211.

Kozma, R. (1994). Will media influence learning? Reframing the debate. Educational Technology, Research and Development, 42(2), 7-19.

Morrison, G. (1994). The media effects question: unresolvable or asking the right question. Educational Technology, Research and Development, 42(2), 41-44.

Morrison, G., Ross, S. \& Kemp, J., (2001). Designing effective instruction (3 ${ }^{\text {rd }}$ ed.). New York: John Wiley \& Sons, Inc.

Reiser, R.A. (1994). Clark's invitation to the dance: an instructional designer's response. Educational Technology, Research and Development, 42(2), 45-48. 
Reiser, R.A. \& Dick, W. (1996). Instructional planning: a guide for teachers $\left(2^{\text {nd }}\right.$ ed.). Needham Heights, MA: Allyn \& Bacon

Shrock, S.A. (1994). The media influence debate: read the fine print, but don't lose sight of the big picture. Educational Technology, Research and Development, 42(2), 49-53.

Smith, P. \& Ragan, T. (1999). Instructional design. Upper Saddle river, NJ: Prentice Hall.

Tyack, D. \& Cuban, L. (1995). Tinkering toward utopia. Cambridge: Harvard University Press.

Willis, J., Johnson, D.L. \& Dixon, P. (1983). Computers, teaching and learning: an introduction to computers in education. Beaverton, OR: Dilithium Press. 
Author Biographies

\section{Nancy B. Hastings}

Nancy B. Hastings received her B.S. in Human Resources Management in 1999, and her M.A. in Training and Development in 2003, both from Oakland University, Rochester, Michigan. She is currently a full-time doctoral student in the Instructional Technology program at Wayne State University, Detroit, Michigan, and works part-time as a lecturer at Oakland University, Rochester, Michigan.

Mrs. Hastings' professional experiences include three years as Corporate Training Manager for a large, privately owned company in the Detroit area where she was responsible for instructional design, classroom facilitation, program evaluation and management of the sales and service training programs and staff. Prior to that she spent 11 years in the manufacturing field, designing safety and quality related instruction. Mrs. Hastings is a member of the International Society for Performance Improvement (ISPI) and the Association for Educational Communications and Technology (AECT).

\section{Monica W. Tracey, Ph.D.}

Monica W. Tracey received her Ph. D. from Wayne State University, Detroit, Michigan in 2001. Her dissertation on "The Construction and Validation of a Systems Design Model Incorporating Multiple Intelligences" completed her doctoral studies in the College of Education majoring in Instructional Technology.

Dr. Tracey is currently an Assistant Professor at Oakland University in Rochester, Michigan where she continues her research on Multiple Intelligences and Instructional Design. She serves as the College of Education Representative on The Dennis Pawley Lean Manufacturing Institute along with several other committees. She is an active member in AECT and on the D\&D Division Review Board for ETR\&D. 